\title{
Making a bad thing worse: adverse effects of stress on drug addiction
}

\author{
Jessica N. Cleck and Julie A. Blendy
}

Department of Pharmacology, University of Pennsylvania School of Medicine, Philadelphia, Pennsylvania, USA.

\begin{abstract}
Sustained exposure to various psychological stressors can exacerbate neuropsychiatric disorders, including drug addiction. Addiction is a chronic brain disease in which individuals cannot control their need for drugs, despite negative health and social consequences. The brains of addicted individuals are altered and respond very differently to stress than those of individuals who are not addicted. In this Review, we highlight some of the common effects of stress and drugs of abuse throughout the addiction cycle. We also discuss both animal and human studies that suggest treating the stress-related aspects of drug addiction is likely to be an important contributing factor to a long-lasting recovery from this disorder.
\end{abstract}

\section{Introduction}

Drug abuse is among the top 3 health problems in the United States in terms of economic and health care costs. The compulsive use of drugs despite serious negative consequences defines addiction as a mental illness (1). To date, however, there are very few effective medications to treat this disease. Addiction is not characterized as a single incident, but rather by a series of events initiated by the acute rewarding effects of drugs followed by a transition into chronic drug use (Figure 1). Many addicts experience periods of abstinence, but frequently relapse to chronic drug taking. The cyclical nature of chronic drug use, involving periods of drug abstinence and subsequent relapse, highlights the presence of this disease throughout the lifetime of an individual. Animal research and human imaging studies have identified the brain circuitry mediating the initial rewarding properties of drugs (1); however, the molecular and cellular mechanisms responsible for the development and persistence of the addicted state remain elusive. Although many factors can contribute to initial and continued drug use, exposure to either psychological or physiological stress at any point in the addiction cycle seems to worsen this disease, augmenting all drug-seeking behaviors, including initial drug taking, drug craving, and relapse $(2,3)$. This Review details the integration of stress and addiction circuitry and discusses the molecular and cellular changes common to both following exposure to stress or drugs of abuse. In addition, current therapies used to treat addiction, in particular stress-induced relapse, are discussed.

\section{Brain circuitry, stress, and addiction}

Mesolimbic dopamine pathway. All drugs of abuse exert their primary rewarding effects on the mesolimbic dopamine reward pathway, which consists of dopamine neurons originating in the ventral tegmental area (VTA) and extending to the nucleus accumbens (NAc) and the prefrontal cortex (PFC) (Figure 2) (4). Psychomotor stimulants, such as cocaine, amphetamine, opiates, nicotine, and

Nonstandard abbreviations used: ACTH, adrenocorticotropin hormone; BNST, bed nucleus of the stria terminalis; CREB, cAMP response element-binding protein; $\mathrm{CRF}$, corticosterone-releasing factor; CRFR, CRF receptor; GR, glucocorticoid receptor; HPA, hypothalamic-pituitary-adrenal (axis); NAc, nucleus accumbens; PFC, prefrontal cortex; PVN, paraventricular nucleus of the hypothalamus; VTA, ventral tegmental area.

Conflict of interest: The authors have declared that no conflict of interest exists. Citation for this article: J. Clin. Invest. 118:454-461 (2008). doi:10.1172/JCI33946. alcohol, in addition to natural rewards, such as sex and food, cause a release of dopamine in the NAc regardless of their mechanism of action (5). Several lines of evidence indicate that the mesolimbic dopamine reward pathway is also responsive to stress. First, in animal models, acute exposure to a stressor, such as footshock (6) and tail pinch (7), produces an increase in dopamine release in the NAc. Second, exposure to either drugs of abuse or stress produces similar alterations in the electrophysiology of neurons in the mesolimbic dopamine reward pathway in animals. Enhanced excitatory synaptic transmission, as evidenced by an increase in glutamate receptor activation, occurs in VTA dopamine neurons following exposure to either stress or any one of several drugs of abuse, including cocaine, nicotine, and alcohol (8). Finally, both stress and drugs of abuse cause alterations in specialized extensions of neurons called dendrites (9-11). Rats subjected to chronic restraint stress exhibit decreases in dendritic branching in the medial PFC (11). Alterations in dendritic branching are also observed following exposure to addictive drugs, with an increase occurring following exposure to cocaine and amphetamine, whereas reductions in branching occur following exposure to morphine $(9,10)$. Together, these findings indicate that stress and drugs of abuse act similarly to affect the neurochemistry, electrophysiology, and morphology of neurons involved in reward pathways.

Molecular changes associated with stress exposure and drug addiction are also similar. Because of the long-lasting nature of addiction, changes in gene expression might be necessary for the development and persistence of this disease. Proteins well situated to effect these long-term changes are regulators of gene transcription. A large body of evidence demonstrates that a member of the leucine zipper family of transcription factors, FosB (in particular, a truncated form of this protein, $\triangle \mathrm{FosB}$ ), accumulates in the NAc following chronic administration of drugs of abuse in rodents (12). Similarly, chronic stress increases $\Delta$ FosB levels in the NAc as well as in the frontal cortex and basolateral amygdala (13). Another member of this same class of transcription factors, cAMP response element-binding protein (CREB), can also function at the intersection of drug reward and stress response. CREB is regulated by both acute and chronic drug treatment throughout brain reward areas $(14,15)$. Various stressors, including shock, repeated immobilization, and forced swim, activate the hypothalamic-pituitary-adrenal (HPA) axis and are associated with increased phosphorylation of CREB in several regions of the brain (16), including the NAc (17). 


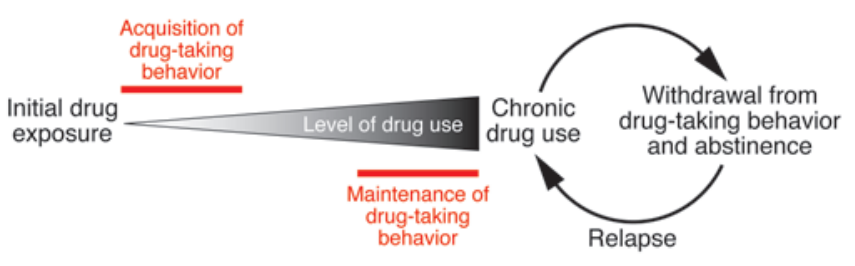

Figure 1

The cycle of addiction. Following the initial exposure to an addictive substance, acquisition of drug taking occurs, in which infrequent drug taking escalates into chronic drug use. Periods of chronic drug use are followed by intervals of withdrawal. These periods of abstinence from the addictive drug can last days, weeks, months, or years. However, most addicts do not remain drug free and relapse back into drug use, creating a vicious cycle. Stress can exacerbate drug taking throughout this process facilitating initial drug exposure, increasing acquisition of drug taking, and causing a relapse to drug-taking behavior during withdrawal.

In addition, a CREB-related transcription factor, inducible cAMP element repressor, demonstrates parallel mRNA changes in the NAc following either amphetamine administration or exposure to a stressor (18). Thus, stress and addictive drugs might act through common molecular mechanisms within similar brain circuits to perpetuate the addiction cycle. However, additional research is necessary to determine whether drugs and stress regulate similar target genes downstream of these transcriptional regulators.

The HPA axis. Most physiological stressors exert their effects on the HPA axis, the primary endocrine stress pathway. Corticosterone-releasing factor (CRF) is secreted from a subregion of the hypothalamus known as the paraventricular nucleus of the hypothalamus (PVN) to stimulate the output of adrenocorticotropin hormone $(\mathrm{ACTH})$. Following its release from the anterior pituitary, ACTH subsequently stimulates the secretion of adrenal glucocorticoids - cortisol in humans and corticosterone in animals - into the bloodstream (Figure 2). Dysfunction of this peripheral stress circuit contributes to various stress-related neuropsychiatric diseases, including addiction (19).

Similar to the mesolimbic dopamine pathway, the HPA axis is activated in rodents and nonhuman primates following acute administration of many addictive substances - including cocaine, amphetamine, ethanol, opiates, and nicotine - and causes increased ACTH and corticosterone levels in plasma (20). Chronic administration of drugs of abuse in the same animal models results in either a sustained increase in HPA axis function, in the case of cocaine and amphetamine, or a reduced effect of the initial activating effects of the drug, in the case of morphine, nicotine, and alcohol (21-24). Human studies demonstrate similar perturbations following illicit drug use, with slight differences. As in animal models, acute administration of cocaine (25), alcohol (26), and nicotine (27) increases cortisol levels, whereas acute exposure to opiates decreases cortisol levels $(28,29)$. Activation of the HPA axis is maintained in cocaine addicts (30), whereas following chronic opiate use, HPA responses are reduced over time (31), a more typical response to repeated exposure to a stressor $(32,33)$. However, it is unclear whether the irregularities observed in the HPA axis following drug administration indicate a vulnerability to addiction or are the result of prolonged drug exposure.

Extrabypothalamic CRF. In addition to activating the HPA axis, CRF can mediate neurotransmission within the CNS. The placement of CRF and its receptors, CRF receptor 1 (CRFR1) and CRFR2, throughout the limbic system and neocortex suggests a critical role for this peptide in affective disorders, including depression, anxiety, and, more recently, addiction (34). CRF expression is modulated by both acute and chronic drug administration (34) as well as by withdrawal from the addictive drug. Cocaine, morphine, and alcohol tend to increase CRF expression acutely; however, the direction in which CRF expression is altered chronically and following withdrawal from these various drugs depends on both the brain region and drug studied (ref. 34 and Table 1). Although smokers often report stress relief as a motivating factor for continued tobacco use, very little information is available detailing the effect of nicotine on these CRF circuits, in particular the effects of both acute and chronic nicotine administration. During nicotine withdrawal, increased activation of CRF-containing cells in the PVN is observed (35), and increased levels of CRF are reported following withdrawal in rats allowed to self administer nicotine (36). The differences in CRF expression between drug classes highlight the distinctive pharmacological and molecular mechanisms throughout the CNS that each drug uses in exerting its addictive properties. Furthermore, the alterations in CRF protein and mRNA observed during the withdrawal period suggest that drug administration causes transcriptional and translational modifications long after the last drug exposure.

Additional brain circuits. Although this Review is focused on the role of stress circuits in the addiction process, it should be noted that these pathways are not isolated in their activity. The central CRF system, the peripheral HPA stress circuits, and the mesolimbic reward pathway are all continuously activated or repressed by complex interactions with other pathways, including the

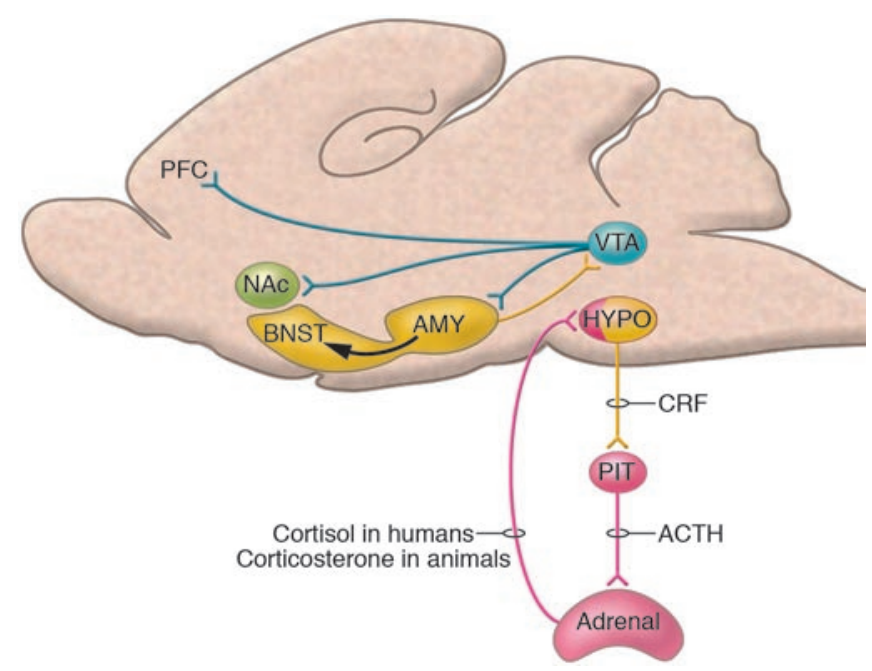

\section{Figure 2}

Reward and stress pathways in the brain. The mesolimbic dopamine reward pathway (blue) is composed of dopamine cell bodies in the VTA that project to the NAc. The VTA also projects to parts of the PFC and the amygdala (AMY). Central CRF circuitry (yellow) consists of CRFcontaining cell bodies located in the central nucleus of the amygdala, which projects to the BNST. CRF projections from the amygdala also innervate the VTA, thus completing the circuit. The hypothalamic CRF projections are directed to the pituitary gland (PIT) located outside the blood-brain barrier. CRF in the pituitary gland stimulates the endocrine output of the HPA axis (red) including the release of ACTH, which acts on the adrenal gland to stimulate the secretion of cortisol in humans and corticosterone in rodents. A negative feedback system allows for cortisol-mediated regulation of continuous CRF production in the HPA axis. 
Table 1

Alterations in mRNA and protein levels of CRF throughout the addiction cycle following exposure to cocaine, morphine, or alcohol

$\begin{array}{ll}\begin{array}{l}\text { Stage of addiction } \\ \text { Acute drug administration }\end{array} & \begin{array}{l}\text { Cocaine } \\ \text { Increased Crf mRNA in PVN and } \\ \text { amygdala (118, 119); decreased CRF } \\ \text { peptide in hypothalamus, hippocampus, } \\ \text { basal forebrain, and frontal cortex (120) } \\ \text { Decreased Crf mRNA in } \\ \text { hypothalamus (118) }\end{array} \\ \text { Withdrawal from drug taking drug administration } & \begin{array}{l}\text { Decreased CRF peptide in hypothalamus } \\ \text { and basal forebrain (66); increased Crf } \\ \text { mRNA in PVN (121); increased CRF } \\ \text { peptide during long-term withdrawal in } \\ \text { amygdala and basal forebrain (122) }\end{array}\end{array}$

\section{Stage of addiction}

amygdala and basal forebrain (122)

\section{Morphine}

Increased CRF peptide in

hypothalamus and BNST $(123,124)$

Increased CRF peptide in

hypothalamus $(123,124)$; decreased

CRF peptide in BNST (124)

No information available

\section{Alcohol}

Increased Crf mRNA in PVN (125)

Increased Crf mRNA in PVN (121);

decreased CRF peptide in

hypothalamus (121)

Increased Crf mRNA in PVN (121); increased CRF peptide during longterm withdrawal in amygdala (122) endogenous opioid and noradrenergic systems $(37,38)$, both of which are important in mediating stress and drug responses. Furthermore, many brain areas throughout the CNS are altered functionally upon exposure to drugs of abuse. Therefore, the interconnectivity throughout the brain needs to be more fully addressed as we continue to determine the molecular mechanisms underlying addiction and the role that stress plays in this process.

\section{Effect of stress on the addiction cycle}

Individuals with stress-related psychiatric disorders, such as anxiety and depression, often engage in some form of drug use. Furthermore, exposure to chronic stressful life events, such as physical or sexual abuse (39), is linked to an increase in nicotine, alcohol, and cocaine usage (40). Recently, a study demonstrated that the greater the physical abuse in childhood (i.e., the longer it lasted), the more likely the subject was to develop drug addiction later in life (41). In addition, stress exposure can increase current drug use and precipitate relapse back to drug-taking behaviors $(2,3)$. Although chronic stress can produce changes in weight loss as well autonomic and endocrine outputs, the significance of these alterations on vulnerability to addiction behaviors has not been systematically characterized. However, the correlative observations in humans that stress exposure can affect various stages of the addiction cycle are supported by evidence from animal studies. Furthermore, these animal studies have enhanced our ability to investigate the underlying mechanisms and molecular targets that are involved in the interaction between stress and addiction.

Acquisition of drug taking. Acquisition is defined as the initial, rewarding exposure to a drug of abuse with development into more chronic use. It has long been hypothesized that exposure to a stressful event or situation would increase the rate of acquisition to drug taking. In animal models, exposure to physiological as well as physical stressors, including social isolation, tail pinch, and footshock, can enhance initial amphetamine and cocaine self administration (42-44). Furthermore, repeated exposure to forced swim stress can augment the rewarding properties of cocaine (45). These studies implicate stress in modulating the initial rewarding effects of addictive drugs.

Corticosterone release via the HPA axis is vital to the acquisition of drug administration. Inhibiting corticosterone release by adrenalectomy or pharmacologic treatment blocks cocaine self administration in rats $(46,47)$. Furthermore, corticosterone release following drug administration in rats increases neuronal activity above the critical levels needed for self administration to occur (48). This additional neuronal activation by the HPA axis is particularly evident at lower doses of cocaine, such that doses not normally rewarding are now readily self administered. These results are consistent with a study that examined corticosterone levels in rats that exhibit different behavioral and endocrine responses to a novel environment (49). Rats that showed increased locomotor activity and high corticosterone levels upon exposure to a novel environment were termed high responders, whereas low responders exhibited decreased locomotor activity and lower corticosterone levels. Following this initial classification, animals were trained to self-administer cocaine. Low responders did not learn to self administer cocaine, whereas robust self administration was observed in rats assessed as high responders. Interestingly, daily corticosterone administration induced and maintained amphetamine self administration in the low-responding rats, effectively switching their behavior to that of high responders (49).

The ability of corticosterone to modulate cocaine reward can be mediated by glucocorticoid receptors (GRs) located on neurons throughout the mesolimbic dopamine reward pathway (50). Adrenalectomized animals exhibit a blunted dopamine response in the NAc following either drug exposure (51) or stress (7). Corticosterone replacement prevents the attenuation of this dopamine response. Furthermore, GR antagonists decrease extracellular dopamine levels in the NAc by 50\% (52), similar to the decrease observed following an adrenalectomy (51). In addition, GR antagonists locally injected into the VTA decrease morphine-induced increases in locomotor activity (52), indicating that activation of GRs in the VTA can mediate dopamine-dependent behavioral outputs. Interestingly, in mice where the gene encoding the GR was deleted specifically in the CNS, a dose-dependent decrease in motivation to self administer cocaine was observed (53). These results suggest that the dopamine increase observed in rodents following either drug administration (51) or stress (7) is dependent, at least in part, on the release of corticosterone from the HPA axis and the subsequent activation of GR.

The role of CRF in the acquisition of drug reward has not been thoroughly investigated. CRF protein and mRNA levels are altered following acute administration of many addictive drugs (34). 
Studies using CRFR1 antagonists demonstrate their involvement in the initial behavioral and biochemical effects of cocaine. For example, pharmacological blockade of CRFR1 inhibits cocaineinduced dopamine release (54) as well as reductions in the rewarding properties of cocaine (54) and locomotor activating effects (54, 55). These studies point to a role of CRF in modulating the initial effects of addictive drugs, but more studies are needed to fully determine the role of CRF in the development of drug addiction.

Withdrawal. Abnormalities in stress circuitry continue following the cessation of drug taking, in both immediate and long-term withdrawal. Activation of the HPA axis, as evidenced by a marked increase in corticosterone levels, occurs following acute withdrawal from most drugs of abuse both in humans and in animal models (20). Interestingly, following this initial activation, basal corticosterone and cortisol levels return to normal in humans and rodents, respectively (20). However, during long-term withdrawal from psychostimulants and opiates, the HPA axis displays an augmented response upon exposure to a stressor. In former cocaine (56) and opiate addicts (57), increased levels of ACTH and cortisol were measured following administration of the chemical stressor metyrapone. Metyrapone blocks the synthesis of cortisol, disrupting the normal negative feedback of cortisol on the hypothalamus and thereby causing activation of the HPA stress pathway (20). Furthermore, in abstinent cocaine users, hyperresponsiveness to emotional and physical stress, as well an increased drug craving, is observed (58), which is consistent with an altered HPA axis. In rats, during acute withdrawal, corticosterone responses are augmented upon exposure to restraint stress (59). These data suggest that the stress response can be sensitized by drug exposure and subsequent withdrawal. In contrast, recent evidence has demonstrated an attenuated response to stress during nicotine withdrawal in animals. Corticosterone levels were substantially lower in rats exposed to restraint stress during nicotine withdrawal, although their basal corticosterone levels were similar (60). Chronic smokers demonstrate increased cortisol secretion $(61,62)$, and a reduction in cortisol after smoking cessation has been associated with increased withdrawal severity and relapse $(63,64)$. Together, these studies demonstrate alterations in the responsiveness of the HPA axis to a stressor during long-term withdrawal, which might play a role in the ability of stressors to reinstate drug seeking well after the drug is removed.

Alterations in CRF peptide and mRNA levels throughout the CNS are observed following acute withdrawal from several drugs of abuse, including cocaine and opiates, and these alterations vary by brain region as well as the drug administered. Interestingly, increases in CRF mRNA in the PVN correlate with increases in anxiety behaviors during ethanol, cocaine, and morphine withdrawal (65-67). In addition, blockade of the CRF system with antagonists or antibodies decreases the anxiety observed in this acute withdrawal phase (65-67). CRFR1 antagonists decreased the physical symptoms of morphine withdrawal in dependent rats (67). Together, these data suggest that the CRF system plays a role in the psychological as well as the physical symptoms of acute withdrawal from addictive drugs. However, the role of CRF or stress circuitry in long-term withdrawal has yet to be elucidated.

Reinstatement of drug seeking. Many theories of addiction hypothesize that stress is one of the primary causes of relapse in human addicts $(2,3)$. Using animal models, several laboratories have demonstrated that exposure to an acute stressor can effectively reinstate drug seeking of various drugs, including opiates, psy- chostimulants, alcohol, and nicotine (68-71). Stress facilitates relapse by activating central CRF brain circuits. Animals that have been trained to self administer drug and then have the drug removed reinitiate lever pressing following an intracerebroventricular CRF injection (72). A distinct circuitry involving CRF in the extended amygdala, an important structure for emotional and effective behavior, has been delineated in mediating stressinduced relapse. Structures comprising the extended amygdala overlap with those of the reward pathway, including the central nucleus of the amygdala, bed nucleus of the stria terminalis (BNST), and parts of the NAc (Figure 2) (73). The significance of this pathway in the addiction cycle is evident primarily in relapse or reinstatement. Inactivation of the CRF projection from the central amygdala to the BNST blocks stress-induced (e.g., by footshock) cocaine reinstatement $(74,75)$, and local injections of D-Phe, a nonspecific CRF receptor antagonist, into the BNST, but not the amygdala, attenuates footshock-induced reinstatement (75). Specifically, CRFR1s localized in the BNST, but not the amygdala or NAc, mediate stress-induced relapse into drug seeking (68). Interestingly, selective CRFR1 antagonists attenuate footshock-induced reinstatement of cocaine or opiate seeking $(68,76)$ but have no effect on drug-induced reinstatement $(72,77)$. These data demonstrate that stress stimulation of the CRF-containing pathway, originating in the amygdala and extending into the BNST, and subsequent activation of CRFR1 localized in the BNST, triggers drug seeking in previously addicted animals.

Recently, CRF has been detected in the VTA, the site of origin of the dopamine neurons of the reward pathway (78). In both cocaine-naive and cocaine-experienced rats, CRF is released into the VTA following an acute footshock; however, the source of this CRF is not known (78). In cocaine-experienced animals, glutamate and dopamine are released in the VTA in conjunction with CRF in response to a stressor. This release of glutamate and dopamine is dependent upon CRF and subsequent activation of its receptors, as local injections of CRF antagonists into the VTA attenuated the release of these 2 neurotransmitters $(78,79)$. In addition, administration of CRFR2 antagonists, but not CRFR1 antagonists, locally into the VTA blocked the ability of footshock to reinstate cocaine seeking in a self-administration paradigm (79). Taken together, these studies suggest a role for CRF in modulating dopamine cell activity, specifically following drug experience.

Although studies have clearly demonstrated a role for CRF in reinstatement of stress-induced drug seeking, very few have examined whether other molecular mechanisms are important in stress-induced reinstatement. The transcription factor CREB, implicated in both stress and addiction, was recently shown to be involved in stress-induced reinstatement. CREB-deficient mice do not exhibit stress-induced reinstatement of cocaine-conditioned place preference (70). However, these mice do exhibit reinstatement of drug seeking to a priming dose of cocaine (70). This deficit in stress- and not drug-induced reinstatement indicates a specific requirement for CREB in stress-induced behavioral responses to drugs of abuse. Of interest, a putative CREB target gene, brainderived neurotrophic factor (BDNF), localized in the VTA and the NAc of the mesolimbic dopamine reward pathway, was increased following withdrawal from chronic cocaine (80). The increase in $\mathrm{BDNF}$ in these brain areas positively correlated with the response of the rats to drug-associated cues (80), and more recent studies demonstrate that BDNF might facilitate relapse to drug-seeking 
behavior (81). Additional experiments detailing the molecular mechanisms of stress-induced reinstatement are needed to fully understand this complex process.

\section{Therapies}

Both animal and human studies have clearly demonstrated a role for stress throughout the addiction process. Addicts describe stress as one of the key reasons for continuing drug use or relapsing back into drug taking following a period of abstinence. Therefore, minimizing the effect of stress throughout the addiction cycle, particularly during the withdrawal period, is essential in the treatment of addiction. However, current treatments for addiction are inadequate, as about half of all addicts relapse back into drug taking. Despite the high levels of relapse, several classes of drug therapies are showing promise in treating some aspects of addiction. Although some of these treatments target the stress and addiction circuits, such as the extrahypothalamic CRF circuits discussed above, others have taken a novel approach in their treatment mechanisms, targeting secondary systems that might modulate stress and addiction pathways.

CRFR1 antagonists. As animal models have clearly demonstrated, CRFR1 antagonists are effective in attenuating stress-induced relapse to drug taking $(76,82-84)$. CP-154,526, a CRFR1 nonpeptide antagonist, attenuates stress-induced relapse to drug seeking in rats (77). Antalarmin, MJL-1-109-2, and R121919, all CRFR1 nonpeptide antagonists, decrease ethanol self administration in ethanol-dependent rats, with no effect on ethanol intake in nondependent rats (85). Furthermore, antalarmin has been shown to decrease ACTH and corticosterone levels in nonhuman primates in addition to decreasing behavioral anxiety scores (86). Together these data suggest that CRFR1 might be an effective therapeutic target for medications to treat drug addiction. However, in the human population, progress toward applying compounds that target this receptor to the treatment of addiction has been slow. Currently, antalarmin is in phase I and phase II clinical trials for the treatment of anxiety and depression, although no results from these studies have been made public (87). In addition, R121919 has been shown in an open-label clinical trial to be effective in reducing depression and anxiety-like symptoms in humans (88, 89 ), and more recently, the high-affinity CRFR1 antagonist NB134041 has demonstrated efficacy in attenuating an elevated stress response both in animals and in humans, but no studies have evaluated the therapeutic value of these compounds in treating the drug-addicted population (90).

Varenicline. Nicotine is believed to be the primary factor responsible for the addictive properties of tobacco use. Nicotine acts on $\alpha 4 \beta 2$ receptors, which are involved in the rewarding aspects of this drug, specifically through the release of dopamine in the NAc (91). Therefore, a partial agonist of this receptor, by blocking the binding of the receptor, might ease withdrawal symptoms. Varenicline, an $\alpha 4 \beta 2$ acetylcholine nicotinic receptor partial agonist, has shown promise in nicotine addiction. As reported in several clinical trials, the rates of continuous abstinence from smoking are higher in those patients given varenicline compared with placebo $(92,93)$. Reduced craving and withdrawal symptoms were also observed $(92,94)$. In animal studies, varenicline reduces nicotine self administration (95), and more recently, rats showed decreased ethanol consumption following acute and chronic varenicline administration (96). As these studies show, varenicline is an effective treatment option for smok- ing cessation. However, no studies have specifically examined this drug during reinstatement in animal models.

Antidepressants. Based on the potential role of CRFR1 antagonists in treating depression, and given that stress can precipitate both depression and addiction, other antidepressant medications have been evaluated over the years for efficacy in treating drug abuse. Bupropion, an atypical antidepressant, has shown significant promise in the treatment of nicotine dependence (97). Bupropion's efficacy in smoking cessation was observed anecdotally by a clinician treating patients for depression (98). Since this keen observation, bupropion has been shown to be effective in numerous clinical trials as a smoking cessation agent, in particular in combination with nicotine replacement therapy (98). Bupropion acts at norepinephrine and dopamine transporters, inhibiting reuptake of these neurotransmitters. In addition, it functions as an antagonist at $\alpha 4 \beta 2$ nicotinic receptors (99). Recently, a study using a rodent model of nicotine dependence demonstrated decreases in physical signs associated with nicotine withdrawal following bupropion administration (100).

Of the classical antidepressants, only desipramine (DMI), a tricyclic antidepressant, has shown promise in treating cocaine addiction. Past studies have reported decreases in cocaine intake in self-administering rats (101) and decreases in cocaine craving in humans following chronic DMI treatment (102). However, a recent study in crack cocaine addicts demonstrated little to no efficacy of DMI treatment (103). Currently, DMI is rarely used to treat cocaine addiction because other medications, such as modafinil, are showing more promise in clinical trials (98). The exact mechanism of action of modafinil is not known, although it has been shown to inhibit the reuptake of dopamine and norepinephrine as well as to activate glutamate and inhibit GABA neurotransmission (104). Of interest, other compounds that target the GABA system, in particular those that increase GABA activation, have been shown to be effective in treating cocaine craving and relapse (98).

Lofexidine. The noradrenergic system has been implicated in stress-induced reinstatement of drug seeking. Lofexidine, an $\alpha 2$ adrenergic receptor agonist, reduces opioid withdrawal symptoms by decreasing noradrenergic outflow in the CNS (105). Animal models have demonstrated that lofexidine attenuates footshock-induced reinstatement of drug seeking (106), as administration of $\alpha 2$ adrenergic receptor agonists or selectively lesioning noradrenergic projections to forebrain areas effectively blocks stress-induced reinstatement in rats $(106,107)$. Furthermore, local injections of noradrenergic antagonists into the BNST and central amygdala inhibited the ability of footshock to reinstate drug seeking (108). In addition, a recent human study showed that a combination of lofexidine and naltrexone, a $\mu$ opioid antagonist, substantially increased abstinence rates in current opiate users as well as decreasing stress-induced drug craving when compared with naltrexone alone (109). Although lofexidine is approved for use in opioid withdrawal in the United Kingdom, more studies are needed to determine fully the role for lofexidine in stress-induced opiate relapse.

Additional medications. Several other medications have been approved for substance abuse, specifically for the treatment of alcoholism. Naltrexone decreases baseline drinking levels as well as alcohol craving and overall number of relapse episodes back into alcohol consumption (110). However, naltrexone is not effective in blocking stress-induced reinstatement in animal models (111), nor has it been effective in treating stress-induced 
drug craving in humans (112). Acamprosate, a modulator of the $\mathrm{N}$-methyl-D-aspartic acid receptor, is also approved to treat alcohol dependence. Used to prevent relapse back into alcoholism, it has been shown to reduce alcohol intake as well as craving (113). In addition, acamprosate alleviates anxiety associated with alcohol withdrawal and increases alcohol abstinence (98). However, little is know regarding the ability of acamprosate to block stressinduced relapse.

\section{Conclusion}

As has been hypothesized in humans, and now demonstrated convincingly in animal studies, stress is one of the key factors in facilitating reward associated with initial drug exposure. In addition, stress increases drug craving and relapse back into drug seeking. Studies have demonstrated a positive correlation of stress and drug craving in humans (114), indicating an activation of reward pathways following exposure to a stressor (115). A significant gap in our understanding of addiction is whether alterations in brain chemistry observed in chronic addicts is caused by environmental factors, such as physical or sexual abuse, which are known to lead to illicit drug use, or by the long-term drug use itself. Recently, it was demonstrated that humans with self-reported increased life stress display increased drug reward to an acute injection of amphetamine (116), further supporting the hypothesis that exposure to a chronic stress environment increases the risk of developing addictive behavior. Furthermore, the high-stress group exhibited a decrease in dopamine release at baseline as well as in response to amphetamine (116), indicating that this decreased dopamine response might constitute a vulnerability to addiction. In a monkey model of social hierarchy, the amount or availability of dopamine D2 receptors was increased in dominant monkeys, whereas no change was observed in subordinate cage mates (117). Interestingly, cocaine was more reinforcing in the subordinate than in the dominant monkeys (117), indicating that environmental modifications of the dopamine system may alter vulnerability to addiction. However, future studies examining the molecular targets and signaling pathways altered by chronic environmental, physical, and psychological stress and their effects on addictive behaviors need to be completed.

Although effective treatments for drug abuse involve both behavioral therapy and medication, the list of medications approved by the FDA for treatment of addiction is limited. Indeed, there are currently no approved medications for cocaine addiction. Furthermore, many of the treatments available are given when the addict is actively using the addictive substance. Current treatments for alcohol, nicotine, and opiate addiction are used to reduce or stop drug intake. For example, naltrexone decreases alcohol intake, allowing for a more productive lifestyle. Bupropion is prescribed in conjunction with nicotine replacement therapy when patients are still smoking. Very few treatments are prescribed during the withdrawal period, in particular to prevent relapse. Over the last 10-15 years, research into the effects of stress on the addiction cycle has identified both peripheral and central CRF systems as key players in linking stress and addiction. Although therapeutic drugs targeting this system are being examined for their treatment efficacy, additional research examining withdrawal and relapse, in particular stress-induced relapse, is needed to further determine putative therapeutic targets.

\section{Acknowledgments}

The authors wish to thank Charles P. O'Brien for critically reading this manuscript. This work was supported by National Institute on Drug Abuse grant DA116-49-01A2 (to J.A. Blendy).

Address correspondence to: Julie A. Blendy, University of Pennsylvania, 125 South 31st Street, Philadelphia, Pennsylvania 191046055, USA. Phone: (215) 898-0730; Fax: (215) 573-2041; E-mail: blendy@mail.med.upenn.edu.
1. Hyman, S.E., and Malenka, R.C. 2001. Addiction and the brain: the neurobiology of compulsion and its persistence. Nat. Rev. Neurosci. 2:695-703.

2. Sinha, R. 2007. The role of stress in addiction relapse. Curr. Psychiatry Rep. 9:388-395.

3. Koob, G., and Kreek, M.J. 2007. Stress, dysregulation of drug reward pathways, and the transition to drug dependence. Am. J. Psychiatry. 164:1149-1159.

4. Spanagel, R., and Weiss, F. 1999. The dopamine hypothesis of reward: past and current status. Trends Neurosci. 22:521-527.

5. Di Chiara, G., and Imperato, A. 1988. Drugs abused by humans preferentially increase synaptic dopamine concentrations in the mesolimbic system of freely moving rats. Proc. Natl. Acad. Sci. U. S. A. 85:5274-5278.

6. Kalivas, P.W., and Duffy, P. 1995. Selective activation of dopamine transmission in the shell of the nucleus accumbens by stress. Brain Res. 675:325-328.

7. Rouge-Pont, F., Deroche, V., Le Moal, M., and Piazza, P.V. 1998. Individual differences in stress-induced dopamine release in the nucleus accumbens are influenced by corticosterone. Eur. J. Neurosci. 10:3903-3907.

8. Saal, D., Dong, Y., Bonci, A., and Malenka, R.C. 2003. Drugs of abuse and stress trigger a common synaptic adaptation in dopamine neurons. Neuron. 37:577-582.

9. Robinson, T.E., and Kolb, B. 1999. Morphine alters the structure of neurons in the nucleus accumbens and neocortex of rats. Synapse. 33:160-162.

10. Robinson, T.E., and Kolb, B. 1999. Alterations in the morphology of dendrites and dendritic spines in the nucleus accumbens and prefrontal cortex following repeated treatment with amphetamine or cocaine. Eur. J. Neurosci. 11:1598-1604.

11. Liston, C., et al. 2006. Stress-induced alterations in prefrontal cortical dendritic morphology predict selective impairments in perceptual attentional set-shifting. J. Neurosci. 26:7870-7874.

12. Nestler, E.J., Barrot, M., and Self, D.W. 2001. DeltaFosB: a sustained molecular switch for addiction. Proc. Natl. Acad. Sci. U. S. A. 98:11042-11046.

13. Perrotti, L.I., et al. 2004. Induction of deltaFosB in reward-related brain structures after chronic stress. J. Neurosci. 24:10594-10602.

14. Walters, C.L., Kuo, Y.C., and Blendy, J.A. 2003. Differential distribution of CREB in the mesolimbic dopamine reward pathway. J. Neurochem. 87:1237-1244.

15. Walters, C.L., Cleck, J.N., Kuo, Y.C., and Blendy, J.A. 2005. Mu-opioid receptor and CREB activation are required for nicotine reward. Neuron. 46:933-943.

16. Bilang-Bleuel, A., Rech, J., De Carli, S., Holsboer, F., and Reul, J.M. 2002. Forced swimming evokes a biphasic response in CREB phosphorylation in extrahypothalamic limbic and neocortical brain structures in the rat. Eur. J. Neurosci. 15:1048-1060.

17. Barrot, M., et al. 2002. CREB activity in the nucleus accumbens shell controls gating of behavioral responses to emotional stimuli. Proc. Natl. Acad. Sci. U. S. A. 99:11435-11440.

18. Green, T.A., et al. 2006. Induction of inducible cAMP early repressor expression in nucleus accumbens by stress or amphetamine increases behavioral responses to emotional stimuli. J. Neurosci.

\section{6:8235-8242.}

19. Goeders, N.E. 2002. Stress and cocaine addiction. J. Pharmacol. Exp. Ther. 301:785-789.

20. Kreek, M.J., and Koob, G.F. 1998. Drug dependence: stress and dysregulation of brain reward pathways. Drug Alcohol Depend. 51:23-47.

21. Ignar, D.M., and Kuhn, C.M. 1990. Effects of specific mu and kappa opiate tolerance and abstinence on hypothalamo-pituitary-adrenal axis secretion in the rat. J. Pharmacol. Exp. Ther. 255:1287-1295.

22. Borowsky, B., and Kuhn, C.M. 1991. Chronic cocaine administration sensitizes behavioral but not neuroendocrine responses. Brain Res. 543:301-306.

23. Benwell, M.E., and Balfour, D.J. 1979. Effects of nicotine administration and its withdrawal on plasma corticosterone and brain 5-hydroxyindoles. Psychopharmacology (Berl). 63:7-11.

24. Spencer, R.L., and McEwen, B.S. 1990. Adaptation of the hypothalamic-pituitary-adrenal axis to chronic ethanol stress. Neuroendocrinology. 52:481-489.

25. Heesch, C.M., et al. 1995. Effects of cocaine on cortisol secretion in humans. Am. J. Med. Sci. 310:61-64.

26. Mendelson, J.H., Ogata, M., and Mello, N.K. 1971. Adrenal function and alcoholism. I. Serum cortisol. Psychosom. Med. 33:145-157.

27. Kirschbaum, C., Wust, S., and Strasburger, C.J. 1992. 'Normal' cigarette smoking increases free cortisol in habitual smokers. Life Sci. 50:435-442.

28. Gosselin, R.E., et al. 1983. Effects of naloxone and an enkephalin analog on serum prolactin, cortisol, and gonadotropins in the chimpanzee. Endocrinology. 
112:2168-2173.

29. Allolio, B., et al. 1987. Effect of oral morphine and naloxone on pituitary-adrenal response in man induced by human corticotropin-releasing hormone. Acta Endocrinol. 114:509-514.

30. Baumann, M.H., et al. 1995. Effects of intravenous cocaine on plasma cortisol and prolactin in human cocaine abusers. Biol. Psychiatry. 38:751-755.

31. Kreek, M.J. 2000. Methadone-related opioid agonist pharmacotherapy for heroin addiction. History, recent molecular and neurochemical research and future in mainstream medicine. Ann. N. Y. Acad. Sci. 909:186-216.

32. Kant, G.J., Bunnell, B.N., Mougey, E.H., Pennington, L.L., and Meyerhoff, J.L. 1983. Effects of repeated stress on pituitary cyclic AMP, and plasma prolactin, corticosterone and growth hormone in male rats. Pharmacol. Biochem. Behav. 18:967-971.

33. Kant, G.J., et al. 1985. Habituation to repeated stress is stressor specific. Pharmacol. Biochem. Behav. 22:631-634

34. Sarnyai, Z., Shaham, Y., and Heinrichs, S.C. 2001. The role of corticotropin-releasing factor in drug addiction. Pharmacol. Rev. 53:209-243.

35. Matta, S.G., Valentine,J.D., and Sharp, B.M. 1997. Nicotine activates NPY and catecholaminergic neurons in brainstem regions involved in ACTH secretion. Brain Res. 759:259-269.

36. George, O., et al. 2007. CRF-CRF1 system activation mediates withdrawal-induced increases in nicotine self-administration in nicotine-dependent rats. Proc. Natl. Acad. Sci. U. S. A. 104:17198-17203.

37. Shippenberg, T.S., Zapata, A., and Chefer, V.I. 2007. Dynorphinand the pathophysiologyofdrugaddiction. Pharmacol. Ther. 116:306-321.

38. Weinshenker, D., and Schroeder, J.P. 2007. There and back again: a tale of norepinephrine and drug addiction. Neuropsychopharmacology. 32:1433-1451.

39. Harrison, P.A., Fulkerson, J.A., and Beebe, T.J. 1997. Multiple substance use among adolescent physical and sexual abuse victims. Child Abuse Negl. 21:529-539.

40. Maddahian, E., Newcomb, M.D., and Bentler, P.M. 1988. Adolescent drug use and intention to use drugs: concurrent and longitudinal analyses of four ethnic groups. Addict Behav. 13:191-195.

41. Lo, C.C., and Cheng, T.C. 2007. The impact of childhood maltreatment on young adults' substance abuse. Am. J. Drug Alcohol Abuse. 33:139-146.

42. Piazza, P.V., Deminiere, J.M., le Moal, M., and Simon, H. 1990. Stress- and pharmacologicallyinduced behavioral sensitization increases vulnerability to acquisition of amphetamine self-administration. Brain Res. 514:22-26.

43. Kosten, T.A., Miserendino, M.J., and Kehoe, P. 2000. Enhanced acquisition of cocaine self-administration in adult rats with neonatal isolation stress experience. Brain Res. 875:44-50.

44. Goeders, N.E., and Guerin, G.F. 1994. Non-contingent electric footshock facilitates the acquisition of intravenous cocaine self-administration in rats. Psychopharmacology (Berl). 114:63-70.

45. McLaughlin, J.P., Marton-Popovici, M., and Chavkin, C. 2003. Kappa opioid receptor antagonism and prodynorphin gene disruption block stress-induced behavioral responses. J. Neurosci. 23:5674-5683

46. Goeders, N.E., and Guerin, G.F. 1996. Effects of surgical and pharmacological adrenalectomy on the initiation and maintenance of intravenous cocaine self-administration in rats. Brain Res. 722:145-152.

47. Mantsch, J.R., Saphier, D., and Goeders, N.E. 1998. Corticosterone facilitates the acquisition of cocaine self-administration in rats: opposite effects of the type II glucocorticoid receptor agonist dexamethasone. J. Pharmacol. Exp. Ther. 287:72-80.

48. Goeders, N.E., and Guerin, G.F. 1996. Role of corticosterone in intravenous cocaine self-administra- tion in rats. Neuroendocrinology. 64:337-348.

49. Piazza, P.V., et al. 1991. Corticosterone levels determine individual vulnerability to amphetamine self-administration. Proc. Natl. Acad. Sci. U. S. A. 88:2088-2092.

50. Harfstrand, A., et al. 1986. Glucocorticoid receptor immunoreactivity in monoaminergic neurons of rat brain. Proc. Natl. Acad. Sci. U. S. A. 83:9779-9783.

51. Barrot, M., et al. 2000. The dopaminergic hyperresponsiveness of the shell of the nucleus accumbens is hormone-dependent. Eur. J. Neurosci. 12:973-979.

52. Marinelli, M., Aouizerate, B., Barrot, M., Le Moal, M., and Piazza, P.V. 1998. Dopamine-dependent responses to morphine depend on glucocorticoid receptors. Proc. Natl. Acad. Sci. U. S. A. 95:7742-7747.

53. Deroche-Gamonet, V., et al. 2003. The glucocorticoid receptor as a potential target to reduce cocaine abuse. J. Neurosci. 23:4785-4790.

54. Lu, L., Liu, Z., Huang, M., and Zhang, Z. 2003. Dopamine-dependent responses to cocaine depend on corticotropin-releasing factor receptor subtypes. J. Neurochem. 84:1378-1386.

55. Przegalinski, E., Filip, M., Frankowska, M., Zaniewska, M., and Papla, I. 2005. Effects of CP 154,526, a CRF1 receptor antagonist, on behavioral responses to cocaine in rats. Neuropeptides. 39:525-533.

56. Schluger, J.H., Borg, L., Ho, A., and Kreek, M.J. 2001. Altered HPA axis responsivity to metyrapone testing in methadone maintained former heroin addicts with ongoing cocaine addiction. Neuropsychopharmacology. 24:568-575.

57. Kreek, M.J., et al. 1984. ACTH, cortisol and betaendorphin response to metyrapone testing during chronic methadone maintenance treatment in humans. Neuropeptides. 5:277-278.

58. Fox, H.C., Hong, K.I., Siedlarz, K., and Sinha, R. 2007. Enhanced sensitivity to stress and drug/ alcohol craving in abstinent cocaine-dependent individuals compared to social drinkers. Neuropsychopharmacology. doi:10.1038/sj.npp.1301470.

59. Mantsch, J.R., et al. 2007. Restraint-induced corticosterone secretion and hypothalamic CRH mRNA expression are augmented during acute withdrawal from chronic cocaine administration. Neurosci. Lett. 415:269-273.

60. Semba, J., Wakuta, M., Maeda, J., and Suhara, T. 2004. Nicotine withdrawal induces subsensitivity of hypothalamic-pituitary-adrenal axis to stress in rats: implications for precipitation of depression during smoking cessation. Psychoneuroendocrinology. 29:215-226.

61. Rohleder, N., and Kirschbaum, C. 2006. The hypothalamic-pituitary-adrenal (HPA) axis in habitual smokers. Int. J. Psychophysiol. 59:236-243.

62. Friedman, A.J., Ravnikar, V.A., and Barbieri, R.L. 1987. Serum steroid hormone profiles in postmenopausal smokers and nonsmokers. Fertil. Steril. 47:398-401.

63. Ussher, M., et al. 2006. Reduction in cortisol after smoking cessation among users of nicotine patches. Psychosom. Med. 68:299-306.

64. al'Absi, M. 2006. Hypothalamic-pituitary-adrenocortical responses to psychological stress and risk for smoking relapse. Int. J. Psychophysiol. 59:218-227.

65. Sarnyai, Z., et al. 1995. Brain corticotropinreleasing factor mediates 'anxiety-like' behavior induced by cocaine withdrawal in rats. Brain Res. 675:89-97.

66. Rassnick, S., Heinrichs, S.C., Britton, K.T., and Koob, G.F. 1993. Microinjection of a corticotropinreleasing factor antagonist into the central nucleus of the amygdala reverses anxiogenic-like effects of ethanol withdrawal. Brain Res. 605:25-32.

67. Skelton, K.H., et al. 2007. The CRF1 receptor antagonist, R121919, attenuates the severity of precipitated morphine withdrawal. Eur. J. Pharmacol. 571:17-24.
68. Wang, J., Fang, Q., Liu, Z., and Lu, L. 2006. Regionspecific effects of brain corticotropin-releasing factor receptor type 1 blockade on footshock-stress- or drug-priming-induced reinstatement of morphine conditioned place preference in rats. Psychopharmacology (Berl). 185:19-28.

69. Gass, J.T., and Olive, M.F. 2007. Reinstatement of ethanol-seeking behavior following intravenous self-administration in wistar rats. Alcohol Clin. Exp. Res. 31:1441-1445.

70. Kreibich, A.S., and Blendy, J.A. 2004. cAMP response element-binding protein is required for stress but not cocaine-induced reinstatement. J. Neurosci. 24:6686-6692.

71. Zislis, G., Desai, T.V., Prado, M., Shah, H.P., and Bruijnzeel, A.W. 2007. Effects of the CRF receptor antagonist d-Phe $\operatorname{CRF}((12-41))$ and the alpha2adrenergic receptor agonist clonidine on stressinduced reinstatement of nicotine-seeking behavior in rats. Neuropharmacology. 53:958-966.

72. Shaham, Y., et al. 1997. Corticotropin-releasing factor, but not corticosterone, is involved in stressinduced relapse to heroin-seeking in rats. J. Neurosci. 17:2605-2614.

73. Hyman, S.E. 1996. Addiction to cocaine and amphetamine. Neuron. 16:901-904.

74. Erb, S., Salmaso, N., Rodaros, D., and Stewart, J. 2001. A role for the CRF-containing pathway from central nucleus of the amygdala to bed nucleus of the stria terminalis in the stress-induced reinstatement of cocaine seeking in rats. Psychopharmacology (Berl). 158:360-365

75. Erb, S., and Stewart, J. 1999. A role for the bed nucleus of the stria terminalis, but not the amygdala, in the effects of corticotropin-releasing factor on stress-induced reinstatement of cocaine seeking. J. Neurosci. 19:RC35.

76. Lu, L., Liu, D., and Ceng, X. 2001. Corticotropinreleasing factor receptor type 1 mediates stressinduced relapse to cocaine-conditioned place preference in rats. Eur. J. Pharmacol. 415:203-208.

77. Shaham, Y., Erb, S., Leung, S., Buczek, Y., and Stewart, J. 1998. CP-154,526, a selective, non-peptide antagonist of the corticotropin-releasing factor 1 receptor attenuates stress-induced relapse to drug seeking in cocaine- and heroin-trained rats. Psychopharmacology (Berl). 137:184-190.

78. Wang, B., et al. 2005. Cocaine experience establishes control of midbrain glutamate and dopamine by corticotropin-releasing factor: a role in stress-induced relapse to drug seeking. J. Neurosci. 25:5389-5396.

79. Wang, B., You, Z.B., Rice, K.C., and Wise, R.A. 2007. Stress-induced relapse to cocaine seeking: roles for the $\mathrm{CRF}(2)$ receptor and CRF-binding protein in the ventral tegmental area of the rat. Psychopharmacology (Berl). 193:283-294.

80. Grimm, J.W., et al. 2003. Time-dependent increases in brain-derived neurotrophic factor protein levels within the mesolimbic dopamine system after withdrawal from cocaine: implications for incubation of cocaine craving. J. Neurosci. 23:742-747.

81. Graham, D.L., et al. 2007. Dynamic BDNF activity in nucleus accumbens with cocaine use increases self-administration and relapse. Nat. Neurosci. 10:1029-1037.

82. Buczek, Y., Le, A.D., Wang, A., Stewart, J., and Shaham, Y. 1999. Stress reinstates nicotine seeking but not sucrose solution seeking in rats. Psychopharmacology (Berl). 144:183-188.

83. Shalev, U., Finnie, P.S., Quinn, T., Tobin, S., and Wahi, P. 2006. A role for corticotropin-releasing factor, but not corticosterone, in acute food-deprivation-induced reinstatement of heroin seeking in rats. Psychopharmacology (Berl). 187:376-384.

84. Erb, S., Shaham, Y., and Stewart, J. 1998. The role of corticotropin-releasing factor and corticosterone in stress- and cocaine-induced relapse to cocaine 
seeking in rats. J. Neurosci. 18:5529-5536.

85. Funk, C.K., Zorrilla, E.P., Lee, M.J., Rice, K.C., and Koob, G.F. 2007. Corticotropin-releasing factor 1 antagonists selectively reduce ethanol self-administration in ethanol-dependent rats. Biol. Psychiatry. 61:78-86.

86. Habib, K.E., et al. 2000. Oral administration of a corticotropin-releasing hormone receptor antagonist significantly attenuates behavioral, neuroendocrine, and autonomic responses to stress in primates. Proc. Natl. Acad. Sci. U. S. A. 97:6079-6084

87. Zoumakis, E., Rice, K.C., Gold, P.W., and Chrousos, G.P. 2006. Potential uses of corticotropinreleasing hormone antagonists. Ann. N. Y. Acad. Sci. 1083:239-251.

88. Zobel, A.W., et al. 2000. Effects of the high-affinity corticotropin-releasing hormone receptor 1 antagonist R121919 in major depression: the first 20 patients treated. J. Psychiatr. Res. 34:171-181.

89. Kunzel, H.E., et al. 2003. Treatment of depression with the CRH-1-receptor antagonist R121919: endocrine changes and side effects. J. Psychiatr. Res. 37:525-533.

90. Ising, M., et al. 2007. High-affinity CRF1 receptor antagonist NBI-34041: preclinical and clinical data suggest safety and efficacy in attenuating elevated stress response. Neuropsychopharmacology. 32:1941-1949.

91. Di Chiara, G. 2000. Role of dopamine in the behavioural actions of nicotine related to addiction. Eur. J. Pharmacol. 393:295-314.

92. Gonzales, D., et al. 2006. Varenicline, an alpha4beta2 nicotinic acetylcholine receptor partial agonist, vs sustained-release bupropion and placebo for smoking cessation: a randomized controlled trial. JAMA. 296:47-55.

93. Tsai, S.T., et al. 2007. A randomized, placebo-controlled trial of varenicline, a selective alpha4beta2 nicotinic acetylcholine receptor partial agonist, as a new therapy for smoking cessation in Asian smokers. Clin. Ther. 29:1027-1039.

94. Glover, E.D., and Rath, J.M. 2007. Varenicline: progress in smoking cessation treatment. Expert Opin. Pharmacother. 8:1757-1767.

95. Rollema, H., et al. 2007. Pharmacological profile of the alpha4beta2 nicotinic acetylcholine receptor partial agonist varenicline, an effective smoking cessation aid. Neuropharmacology. 52:985-994.

96. Steensland, P., Simms, J.A., Holgate, J., Richards, J.K., and Bartlett, S.E. 2007. Varenicline, an alpha4beta2 nicotinic acetylcholine receptor partial agonist, selectively decreases ethanol consumption and seeking. Proc. Natl. Acad. Sci. U. S. A. 104:12518-12523.

97. Dwoskin, L.P., Rauhut, A.S., King-Pospisil, K.A., and Bardo, M.T. 2006. Review of the pharmacology and clinical profile of bupropion, an antidepressant and tobacco use cessation agent. CNS Drug
Rev. 12:178-207.

98. O'Brien, C.P. 2005. Anticraving medications for relapse prevention: a possible new class of psychoactive medications. Am. J. Psychiatry. 162:1423-1431.

99. Slemmer, J.E., Martin, B.R., and Damaj, M.I. 2000 Bupropion is a nicotinic antagonist. J. Pharmacol. Exp. Ther. 295:321-327.

100.Wing, V.C., and Shoaib, M. 2007. Examining the clinical efficacy of bupropion and nortriptyline as smoking cessation agents in a rodent model of nicotine withdrawal. Psychopharmacology (Berl). 195:303-313.

101.Markou, A., Hauger, R.L., and Koob, G.F. 1992. Desmethylimipramine attenuates cocaine withdrawal in rats. Psychopharmacology (Berl). 109:305-314.

102.Kosten, T., et al. 1992. Intravenous cocaine challenges during desipramine maintenance. Neuropsychopharmacology. 7:169-176.

103. Campbell, J., et al. 2003. Comparison of desipramine or carbamazepine to placebo for crack cocainedependent patients. Am. J. Addict. 12:122-136.

104. Ballon, J.S., and Feifel, D. 2006. A systematic review of modafinil: Potential clinical uses and mechanisms of action. J. Clin. Psychiatry. 67:554-566.

105.Cox, S., and Alcorn, R. 1995. Lofexidine and opioid withdrawal. Lancet. 345:1385-1386.

106. Erb, S., et al. 2000. Alpha-2 adrenergic receptor agonists block stress-induced reinstatement of cocaine seeking. Neuropsychopharmacology. 23:138-150.

107. Shaham, Y., Highfield, D., Delfs, J., Leung, S., and Stewart, J. 2000. Clonidine blocks stress-induced reinstatement of heroin seeking in rats: an effect independent of locus coeruleus noradrenergic neurons. Eur. J. Neurosci. 12:292-302.

108.Leri, F., Flores, J., Rodaros, D., and Stewart, J. 2002. Blockade of stress-induced but not cocaineinduced reinstatement by infusion of noradrenergic antagonists into the bed nucleus of the stria terminalis or the central nucleus of the amygdala. J. Neurosci. 22:5713-5718.

109.Sinha, R., Kimmerling, A., Doebrick, C., and Kosten, T.R. 2007. Effects of lofexidine on stress-induced and cue-induced opioid craving and opioid abstinence rates: preliminary findings. Psychopharmacology (Berl). 190:569-574.

110. Volpicelli, J.R., Alterman, A.I., Hayashida, M., and O'Brien, C.P. 1992. Naltrexone in the treatment of alcohol dependence. Arch. Gen. Psychiatry. 49:876-880.

111.Liu, X., and Weiss, F. 2002. Additive effect of stress and drug cues on reinstatement of ethanol seeking: exacerbation by history of dependence and role of concurrent activation of corticotropin-releasing factor and opioid mechanisms. J. Neurosci. 22:7856-7861.

112.Hyman, S.M., Fox, H., Hong, K.I., Doebrick, C., and Sinha, R. 2007. Stress and drug-cue-induced craving in opioid-dependent individuals in naltrexone treatment. Exp. Clin. Psychopharmacol. 15:134-143.
113.Mann, K., Lehert, P., and Morgan, M.Y. 2004. The efficacy of acamprosate in the maintenance of abstinence in alcohol-dependent individuals: results of a meta-analysis. Alcohol. Clin. Exp. Res. 28:51-63.

114.Sinha, R., Fuse, T., Aubin, L.R., and O'Malley, S.S. 2000. Psychological stress, drug-related cues and cocaine craving. Psychopharmacology (Berl). 152:140-148.

115.Duncan, E., et al. 2007. An fMRI study of the interaction of stress and cocaine cues on cocaine craving in cocaine-dependent men. Am. J. Addict. 16:174-182.

116. Oswald, L.M., et al. 2007. Impulsivity and chronic stress are associated with amphetamine-induced striatal dopamine release. Neuroimage. 36:153-166.

117. Morgan, D., et al. 2002. Social dominance in monkeys: dopamine D2 receptors and cocaine selfadministration. Nat. Neurosci. 5:169-174.

118.Zhou, Y., et al. 1996. Corticotropin-releasing factor and type 1 corticotropin-releasing factor receptor messenger RNAs in rat brain and pituitary during "binge"-pattern cocaine administration and chronic withdrawal. J. Pharmacol. Exp. Ther. 279:351-358.

119. Rivier, C., and Lee, S. 1994. Stimulatory effect of cocaine on ACTH secretion: role of the hypothalamus. Mol. Cell. Neurosci. 5:189-195.

120.Sarnyai, Z., et al. 1993. Alterations of corticotropin-releasing factor-like immunoreactivity in different brain regions after acute cocaine administration in rats. Brain Res. 616:315-319.

121.Milanes, M.V., Laorden, M.L., Chapleur-Chateau, M., and Burlet, A. 1998. Alterations in corticotropin-releasing factor and vasopressin content in rat brain during morphine withdrawal: correlation with hypothalamic noradrenergic activity and pituitary-adrenal response. J. Pharmacol. Exp. Ther. 285:700-706

122.Zorrilla, E.P., Valdez, G.R., and Weiss, F. 2001. Changes in levels of regional CRF-like-immunoreactivity and plasma corticosterone during protracted drug withdrawal in dependent rats. Psychopharmacology (Berl). 158:374-381.

123.Suemaru, S., Hashimoto, K., and Ota, Z. 1985 Effects of morphine on hypothalamic corticotropin-releasing factor (CRF), norepinephrine and dopamine in non-stressed and stressed rats. Acta Med. Okayama. 39:463-470.

124.Milanes, M.V., Laorden, M.L., Chapleur-Chateau, M., and Burlet, A. 1997. Differential regulation of corticotropin-releasing factor and vasopressin in discrete brain regions after morphine administration: correlations with hypothalamic noradrenergic activity and pituitary-adrenal response. Naunyn Schmiedebergs Arch. Pharmacol. 356:603-610.

125.Ogilvie, K.M., and Rivier, C. 1997. Gender difference in hypothalamic-pituitary-adrenal axis response to alcohol in the rat: activational role of gonadal steroids. Brain Res. 766:19-28. 